\title{
PROSPECTS AND CHALLENGES OF UPGRADING UNTRAINED TEACHERS IN SUB-SAHARAN AFRICA: THE CASE OF GHANA
}

\author{
Seidu Sofo ${ }^{1}$ \\ Southeast Missouri State University, USA \\ Emmanuel Thompson \\ Southeast Missouri State University, USA \\ Tontie L. Kanton \\ University of Ghana, Ghana
}

\begin{abstract}
Many countries in Sub-Saharan Africa have used non-traditional teacher education programs to address the perpetual problem of inadequate provision of trained teachers. Using the bioecological systems theory, the present study examined untrained teacher trainees' perceptions about the prospects and challenges of upgrading untrained teachers in Ghana. Participants included 248 untrained teachers (39.4\% males, 60.6\% females) enrolled in the Untrained Teachers Diploma in Basic Education (UTDBE) program at two colleges of education in the Northern Region of Ghana. A 5-point Likert questionnaire consisting of nine predictors served as the main data source. The predictors were: attitude, program cost, admission requirements, autonomy support, self-efficacy, social support, childcare, curriculum and instruction, and political interference. The questionnaire also elicited the following demographic information: teaching experience, year in program, grade level taught, level of education attained, age, trainees' sex, and marital status. The response variable was the extent to which the UTDBE was achieving its goals. The questionnaire had a Cronbach's alpha of .728. The lasso-penalized logistic regression model was used to determine important predictors of the response variable. Overall, 90.72\% of the trainees indicated the program was achieving its goals to some degree. The optimal predictive model identified four (4) important predictors: self-efficacy, social support, attitude, and autonomy support in descending order of importance in terms of the extent to which the program was achieving its goals. In conclusion, individual factors, trainees' direct environment, and autonomy-supportive teacher education classrooms influenced untrained teacher trainees' perceptions of the extent to which their teacher education program was achieving its goals.
\end{abstract}

Keywords: bioecological systems theory, Ghana, self-efficacy, social support, untrained teachers

${ }^{1}$ Correspondence: One University Plaza, Cape Girardeau, MO 63701, USA; ssofo@semo.edu 


\section{Introduction}

Many schools in Sub-Saharan Africa (SSA) are staffed with unqualified teachers as a result of the rapid expansion of access to education (UNESCO, 2014). Consequently, countries in SSA have embarked on teacher education reforms as part of overall education reforms. The success of educational reform efforts in SSA greatly depends upon the provision of adequate qualified teachers, especially in the deprived areas. This is consistent with the United Nation's (UN) Sustainable Development Goal (SDG) Goal 4, Target 4.c that aims to increase the supply of qualified teachers by the year 2030 (UN, 2015). It is paramount that the quality of instruction students receive is inevitably linked to teachers' knowledge, professional skills and competences (Adentwi, 2002; Palmer, 2005). Inadequate provision of teachers has been a result of overreliance on traditional teacher training programs. Thus, non-traditional teacher education programs are critical for the provision of quality education in deprived communities because trained teachers are unwilling to accept postings to deprived communities, causing the need for such communities to grow their own trained teachers (Kwaah \& Palojoki, 2018). One such initiative to address the acute shortage of teachers in Ghana is the Untrained Teachers Diploma in Basic Education (UTDBE) program. The main objective of the UTDBE is to provide opportunities for all serving untrained teachers to have access to professional teacher training (Ghana Education Service, 2003).

As a result of the perpetual problem of inadequate provision of trained teachers especially in the deprived regions, countries in SSA have used several measures to address the inequitable distribution of teachers (Mulkeen, 2010). First, some countries use financial incentives to encourage qualified teachers to accept postings to schools in deprived communities. Second, schools in some countries advertise for and recruit their own teachers. Third, others recruit unqualified teachers and provide in-service training. This measure provides opportunities for people from deprived areas to gain a professional qualification while remaining in their home areas (Mulkeen, 2010).

Non-state actors have experimented with non-conventional systems of schooling (Farrell \& Hartwell, 2008). These alternative approaches have been termed "complimentary education” (Casely-Hayford \& Hartwell, 2010; Farrell \& Hartwell, 2008). Key features of these approaches include serving underserved areas; implementing locally relevant curriculum; and providing teachers with no formal preservice training with mentoring and supervision. Non-state actors often collaborate with governmental agencies in the organization and implementation of these alternative approaches (Casely-Hayford, 2003).

Teachers play a critical role in the development of their communities and respective countries at large. Teachers bring about change and development in several ways. First, they serve to bring about social change in their communities. Teachers in SSA are being called upon to be proponents of social justice to promote peace and social cohesion, especially in war-torn areas (Sayed, Badroodien, Salmon, \& McDonald, 2016). For example, post-genocide Rwanda implemented a competence-based curriculum to promote social cohesion and peacebuilding (Ndabaga, Ntahomvukiye, \& Omar, 2018). The success of the new curriculum depended upon teachers upgrading their knowledge and "their understanding of and adherence with the rationale behind the new curriculum" (Ndabaga et al., 2018: 110). Second, teachers help their families with reading and writing, and they also educate their families and communities about health promotion programs relating to hygiene and sanitation and agriculture (Casely-Hayford \& Hartwell, 2010). Finally, the provision of qualified teachers enhances the quality of education, which in turn has the potential for poverty reduction. One of the most effective ways of reducing poverty and increasing upward economic mobility is by increasing the human capital of the poor by producing an educated workforce (Bolda et 
al., 2017). According to the World Bank (2018), each additional year of education results in a 6-10 percent increase in earnings. In addition, one percent increase in the working population with primary school completion can lead to an increase of $0.4 \%$ reduction in poverty rates (World Bank, 2018).

\section{Theoretical Framework}

The bioecological model (Bronfenbrenner \& Morris, 1998) of human development served as the theoretical framework for the study. The model focuses on explaining how the interactions between individual characteristics and the environment influence development and behavior. Relating to the present study, the bioecological model provides insight on how the interaction between untrained teachers and their environment or systems would explain perceptions of non-traditional teacher education programs such as the UTDBE.

The bioecological model deals with the interrelations among four concepts: process, person, context, and time (Bronfenbrenner \& Morris, 1998; Bronfenbrenner, 2005). The process encompasses the interactions the individual has with the immediate environment. These interactions must be regular to be effective (Bronfenbrenner \& Morris, 1998). The teacher trainee, for example, interacts regularly with students, other teachers, and headteachers/headmasters during the in-service component of the program. The biological aspect of the person involves the personal characteristics of the individual. These could be demand characteristics such as the age or gender of the individual. Resource characteristics refer to mental and emotional characteristics such as prior experiences, skills, and intelligence. The third type of characteristics are those that relate to temperament, motivation, and persistence. Personal characteristics that relate to the present study include trainees' sex, marital status, self-efficacy, and their attitudes toward their teacher education program.

The context or environment examines four interrelated systems: microsystem, mesosystem, exosystem, and macrosystem. The microsystem influences the individual daily. For teacher trainees, home influences include parents, siblings, extended family members, and peers. At school, the trainees will be impacted by their students, other teachers in the school, and the headteachers/headmasters (trainees' supervisors). During the periodic residential sessions on the campus of trainees' respective colleges of education, influences will be other trainees, tutors/lecturers, and staff of their respective institutions. Both the home and school are in the same environment; with the school being more distant than the home. The mesosystem is a system of two or more microsystems. For example, family members' involvement in the teacher trainee's education is an example of interaction between two microsystems. The present study examined the extent to which family members were supportive of teacher trainees' pursuance of teacher training. The next context is the exosystem-settings that affect individuals but in which they do not directly participate. These are less visible and more distant influences on the individual. It is worth noting that the present study did not address this context (Tudge, Mokrova, Hatfield, \& Karnik, 2009).

The macrosystem includes influences that occur at the cultural level such as sociocultural beliefs about colleges of education and the teaching profession. Decisions at this level influence individuals even though they are not in direct contact with this level. For example, policy decisions about the colleges of education do affect trainees' participation in their teacher education programs. The present study examined the influence of institutionallevel policy decisions on the attainment of the goals of the program. The element of time involves change or continuity across time. The present study examined trainees' number of 
years teaching, the number of years in the program and their effects on trainees' perceptions of their teacher education program.

\section{Purpose of the Study}

The present study provided the opportunity to gain insight into how individual and environmental factors impact teacher trainees' perspectives of their non-traditional teacher education program. The primary purpose of the study was to examine untrained teacher trainees' perceptions about the prospects and challenges of upgrading untrained teachers in Ghana. The secondary purpose was to examine the extent to which the non-traditional teacher education program (UTDBE) was achieving its goals, from the perspectives of the untrained teacher trainees. The study attempted to answer the following question: What individual and environmental factors predict untrained teacher trainees' perceptions of the extent to which the UTDBE was achieving its goals?

\section{Significance of the Study}

An understanding of how individual and environmental factors affect trainees' perceptions of and participation in non-traditional teacher education programs would empower policy makers and educators to identify cost-effective strategies for producing trained teachers especially for deprived communities. This is pertinent to SSA countries, most of which are low income economies. The success of a teacher education program depends to a large extent upon the ability to identify those factors that facilitate or hinder the implementation of these programs. Thus, it is pertinent to identify those factors that would increase the odds of success for teacher education programs. Similarly, it is paramount to identify the challenges facing these programs in SSA and other low-income countries in order to mitigate any potential barriers.

Personal characteristics of teacher trainees, their immediate environmental contexts, and policy decisions are factors that could affect their professional training. The present study examined the influence of personal characteristics such as trainees' sex, marital status, selfefficacy, and their attitudes on their participation in the teacher education program. In addition, the study investigated the extent to which trainees' family members and peers were supportive of their pursuance of teaching as a profession. The family kinship system in Africa is losing its influence on society due to globalization. Thus, it is important to investigate the degree of support teacher trainees receive from family members. Furthermore, the present study examined the impact of policy-related decisions such as program cost, admission requirements, curriculum and instruction, and political interference on trainees' perspectives of their professional training. Inservice or school-based teacher education has been shown to be more cost-effective than traditional residential programs. Thus, the inclusion of these variables in the study was significant in identifying those factors critical to the success of non-traditional teacher education programs.

In summary, identifying prospects of school-based teacher education programs would help governments and educators in SSA and other low-income economies create enabling environments and conditions for the success of such programs. Additionally, findings from the study would help policy makers and educators identify strategies to mitigate any challenges encountered by trainees. 


\section{Method}

\section{Participants}

Participants included a purposive sample of 248 (56.85\% males and $43.15 \%$ females) untrained teachers enrolled in a non-traditional teacher education program (UTDBE) at two colleges of education in the Northern Region of Ghana. Participants were aged 20-50 years $(\mathrm{M}=29.21$; $\mathrm{SD}=5.49)$. They had teaching experiences ranging from one to five years $(\mathrm{M}=$ $3.70 ; \mathrm{SD}=1.15)$. The number of years enrolled in the UTDBE program ranged from two to three years $(\mathrm{M}=2.22 ; \mathrm{SD}=.42)$. The sample consisted of married $(52.42 \%)$ and single $(42.34 \%)$ trainees. The remaining $2.24 \%$ were in the other category. The trainees taught the following grade levels: Kindergarten (20.20\%), Primary 1 (10.50\%), Primary $2(15.70 \%)$, Primary 3 (16.50\%), Primary $4(13.30 \%)$, Primary 5 (9.30\%), and Primary $6(14.50 \%)$.

The highest level of education attained by the trainees included: Middle School Leaving Certificate (MSLC), Basic Education Certificate Examination (BECE), West Africa Senior School Certificate Examinations (WASSCE) or the Senior Secondary School Examination (SSSCE), and Other. The MSLC, the lowest level of education, was discontinued in the $1980 \mathrm{~s}$ when Ghana introduced the new educational system with the junior secondary school (now junior high school) replacing the middle school. BECE is obtained at the end of the junior high school education. Students sit for the WASSCE/SSSCE at the end of their senior secondary school education. The percentage of trainees in each category were: MLSC (1.61\%); BECE (0.81\%), WASSCE/SSSCE (77.82\%), and Other (19.76\%).

The general requirements for the admission to the Diploma in Basic Education at the colleges of education are credits in three core and two elective WASSCE/SSSCE subjects. However, not all qualified candidates get admitted to the colleges of education due to the quotas allotted to the colleges. Thus, it is not uncommon for some qualified candidates who do not gain admission to the colleges of education to enroll in the UTDBE program.

\section{Study Site}

Participants were enrolled in a non-traditional teacher education program (UTDBE) at the time of the study. The program is aimed at upgrading the content knowledge and teaching methods of untrained teachers (Ministry of Education, 2012). Program objectives include assisting all serving untrained teachers to have access to professional teacher training; improving the quality of teaching and learning, especially in the disadvantaged communities; and increasing the number of trained teachers by training the untrained teachers. The program consists of three components: distance learning modules, school-based professional development, and periodic residential sessions on the campus of trainees' respective colleges of education (Associates for Change, 2016; GES, 2003). As a nonconventional teacher preparation program, the curriculum is made up of four content areas: core foundation courses, education and professional studies, practical activities, and general studies (GES, 2003).

However, the main challenges facing non-traditional programs (UTDBE) include financial challenges, marital issues, and poor academic performance as reasons for teacher trainees dropping out of the UTDBE (Associates for Change, 2016). Research has shown that UTDBE newly qualified teachers had lower entry grades to teacher education programs than their counterparts with Diploma of Basic Education (DBE) who entered colleges of education directly from the senior high school. Similarly, UTDBE teachers had lower achievement in colleges of education (Kwaah \& Palojoki, 2018) than their DBE (traditional teacher education program) counterparts. However, while DBE teachers tended to perform better on core subjects, UTDBE teachers performed better on practical course work (Associates for Change, 
2016). The UTDBE teachers used more practical activities such as group work than DBE teachers, because UTDBE teachers have had some teaching experience, and thus had developed some pedagogical skills (Kwaah \& Palojoki, 2018).

\section{Instrument}

A questionnaire, developed for the study, served as the main data source. The 20-item questionnaire, adapted from Sofo and Thompson (2018), used a 5-point Likert scale of strongly disagree, disagree, neutral, agree, and strongly agree. The questionnaire consisted of nine predictors: attitude (ATT), program cost (PC), admission requirements (AR), autonomy support (AS), self-efficacy (SE), social support (SSP), child care (CC), curriculum and instruction (CI), and political interference (PI). ATT, PC, AR, PI, and CC each consisted of one item. The predictors $\mathrm{SE}$ and $\mathrm{AS}$ consisted of two and three items respectively. CI and SSP consisted of four and five items respectively (see Appendix A). A high rating (5 or 4) represented a positive rating while a low rating ( 1 or 2 ) represented a negative rating. In this study, a positive rating represented a prospect or the likelihood of the program succeeding while a negative rating represented a challenge or a barrier to the success of the program from the trainees' perspectives. However, one item for CI- "The number of courses for the UTDBE program should be reduced"-was reverse coded. That is, a " 5 " rating for this item was coded as " 1 " and vice versa. In addition to the nine predictors, the questionnaire elicited the following demographic information: teaching experience, year in program, grade level taught, level of education attained, age, trainees' sex, and marital status (see Appendix A). Thus, in fitting all statistical models in this study, we used the 16 predictors. The predictor variables were selected based on the literature on learning and teacher education. The associated response variable was the extent to which the UTDBE was achieving its goals. The item, "In my opinion, the UTDBE program is currently achieving its goals," served as the response variable. The questionnaire had a Cronbach's alpha of .728. The four predictors with more than one item had the following Cronbach's alphas: AS (.620), SSP (.745), CI (.609), and SE (.736).

The authors validated and established reliability for the initial questionnaire which consisted of 24 items. First, the initial questionnaire was given to one teacher educator with a doctorate degree and two college of education tutors with master's degrees to establish content validity. The three teacher education experts were asked to comment on the appropriateness of the items for each of the nine predictors. That is, their comments were to indicate the extent to which each item measured the predictor it was purported to measure. Two items, one each from PC and AR, were deleted based on the experts' suggestions. Second, the resulting 22-item questionnaire was administered to the participants. Third, Cronbach's alpha analyses were conducted on four of the predictors with more than one item: AS, SSP, CI, and SE. Based on the reliability analyses using Cronbach's alpha, two additional items (one each from PC and CI) were deleted. Deletion of the two items resulted in higher Cronbach's alphas for the two predictors. Finally, a Cronbach's alpha analysis was conducted for the final 20-item questionnaire to determine the internal consistency (reliability) of the items.

\section{Procedures}

The Human Subjects Committee at the first author's institution approved the study. The two colleges of education granted permission for the study to be conducted at their institutions. Furthermore, participants provided written consent prior to completing the questionnaire. The trainees were in residence on the campuses of their respective colleges of 
education at the time of data collection. Two tutors, one each from the two colleges of education, administered the questionnaire to the participants in their classrooms. The completed questionnaires were returned to the first author in sealed envelopes.

\section{Data Analysis}

\section{Logistic Regression Model}

Research in education has called for the modeling, analysis, and prediction of a dichotomous outcome using a binary logistic regression model. The central mathematical concept that underlies logistic regression is the logit (i.e. the natural logarithm of an odds ratio). Given a dichotomous outcome coded in the form $Y \in\{0,1\}$, the linear logistic model is often used. It models the log-likelihood ratio as the linear combination:

$\log \frac{\operatorname{Pr}(Y=1 \mid X=x)}{\operatorname{Pr}(Y=0 \mid X=x)}=\beta_{0}+\beta^{T} x$

where $X=\left(X_{1}, X_{2}, \cdots, X_{p}\right)$ is a vector of predictors, $\beta_{0} \in R$ is an intercept term, and $\beta \in R^{p}$ is a vector of regression coefficients. Inverting this transformation yields an expression for the conditional probability:

$\operatorname{Pr}(Y=1 \mid X=x)=\frac{\mathrm{e}^{\beta_{0}+\beta^{T} x}}{1+\mathrm{e}^{\beta_{0}+\beta^{T} x}}$.

The logistic model parameters are typically estimated by maximizing the binomial loglikelihood of the data. While this approach works quite well in most applications, it fails in a situation known as separation (Zorn, 2005).

\section{Problem of Separation}

Separation occurs in models of dichotomous outcome data when one predictor variable perfectly predicts zeros, ones, or both. Separation can also occur when a combination of predictor variables perfectly estimates zeros, ones, or both (Geyer, 2009). For a dichotomous predictor variable $X_{i}$ complete separation occurs when $X_{i}$ perfectly estimates both zeros and ones. Quasi-complete separation occurs when predictors perfectly estimates either zeros or ones, but not both (Zorn, 2005).

The nonproblematic case is where there is an overlap and therefore reasonable maximum likelihood estimates exist. However, for the case of complete or quasi-complete separation, finite maximum likelihood estimates do not exist; therefore, the usual approach to computing standard errors of the estimates fails (Zorn, 2005). For instance, the likelihood function under complete separation is monotonic, this means the finite maximum likelihood estimate does not exist (Rainey, 2016). Also, since the logistic regression curve lies strictly between zero and one, this likelihood cannot be obtained, only reaching asymptotically. Thus, the likelihood function under quasi-complete separation also monotonically increases as the coefficient of $X_{i}$ increases, which means that the maximum likelihood estimate does not exist (Rainey, 2016).

The data used in this study had a problem of separation. To circumvent this problem, we employed a regularization or penalization technique to obtain a stable fit in our model and correctly estimate parameters. The next sub-section provides a brief but concise review of the penalized regression method used (Efron \& Hastie, 2016). 


\section{Lasso-Penalized Logistic Model}

To fit generalized linear models (GLM) with an $l_{1}$ (lasso) penalty, maximizing the likelihood, or equivalently minimizing the negative log-likelihood is given by:

$$
\min _{\beta_{0}, \beta}\left\{-\frac{1}{N} \boldsymbol{l}\left(\beta_{0}, \beta ; \mathbf{y}, \mathbf{X}\right)+\lambda|| \beta \|_{1}\right\}
$$

Note that $\mathbf{y}$ is the $N$-vector of outcomes and $\mathbf{X}$ is the $N \times p$ matrix of predictors and the specific form of the log-likelihood $\boldsymbol{l}$ follows the GLM approach. form:

Consider the logistic model (1), the negative log-likelihood with $l_{1}$ penalty takes the

$$
\frac{1}{N} \sum_{i=1}^{N} \log \left(1+e^{-y_{i} f\left(x_{i} ; \beta_{0}, \beta\right)}+\lambda\|\beta\|_{1}\right)
$$

where $f\left(x_{i} ; \beta_{0}, \beta\right):=\beta_{0}+\beta^{T} x_{i}$. For a given predictor-response pair $(x, y)$, the product $y f(x)$ is referred to as the margin - a positive margin means a correct classification, whereas a negative margin means an incorrect classification. We used the glmnet package in $\mathrm{R} / \mathrm{RStudio}$ to fit the lasso-penalized logistic model. The glmnet package uses a proximalNewton iterative approach, which repeatedly approximates the negative log-likelihood by a quadratic function (Lee, Sun \& Saunders, 2014).

In all there were 248 observations with few scattered missing observations. The multivariate imputation via Chained Equation (MICE) within R was used to impute missing values. In fitting the lasso-penalized logistic regression model roughly $70 \%$ of the data were used (in-sample data) while approximately 30\% were used for validation (out-sample data) of the fitted model. The metric used to evaluate the performance of the fitted model is the misclassification error rate based on the out-sample data. Misclassification error is where a correct response is incorrectly classified by the fitted model.

Descriptive and inferential statistics were used to analyze the data. First, frequency and percentage distributions of the degree of response (rating on a 5-point scale) were computed for each predictor and the response variable (see Table 1). Second, a lasso-penalized logistic regression model was fitted, and the most important predictors of the response variable were determined (see Table 2 ). The predictors considered were as follows: ATT, PC, AR, AS, SE, SSP, CC, CI, PI, teaching experience, year in program, grade level taught, level of education attained, age, trainees' sex, and marital status.

The lasso-penalized logistic regression model addressed two concerns: the first solving the problem of separation and the second controlling for multicollinearity among the predictors. Also, the lasso-penalized logistic regression model has the property of shrinking some of the regression coefficients to exactly zero. That is, it simultaneously does both shrinkage and variable selection.

\section{Results}

\section{Descriptive data for predictors and response variable}

The primary purpose of the present study was to examine untrained teacher trainees' perceptions about the prospects and challenges of upgrading untrained teachers through the 
UTDBE program in Ghana. A high rating represented a positive rating while a low rating represented a negative rating. Table 1 presents frequencies and percentages for the predictors and response variable. The data showed that $94.75 \%$ of trainees strongly agreed or agreed that the program had increased their SE. Similarly, 93.15\% indicated they had positive ATT toward the program. Alternatively, CC (28.23\%) showed the lowest percentage of trainees in the strongly agreed or agreed categories, followed by PI (47.48\%). The predictor with most trainees in the neutral category was CI (40.73\%), followed by AR (31.45\%). Overall, 90.72\% of the trainees strongly agreed or agreed that the program was achieving its goals to some degree. Only $5.24 \%$ of trainees were neutral in their responses to the item that the program was achieving its goals to some degree.

\section{Table 1: Frequencies and Percentages for Predictors and Response Variable}

\begin{tabular}{|c|c|c|c|c|c|}
\hline Variable & $\begin{array}{l}\text { Strongly } \\
\text { Disagree }\end{array}$ & Disagree & Neutral & Agree & $\begin{array}{c}\text { Strongly } \\
\text { Agree }\end{array}$ \\
\hline & $\mathrm{f} / \%$ & $\mathrm{f} / \%$ & $\mathrm{f} / \%$ & $\mathrm{f} / \%$ & $\mathrm{f} / \%$ \\
\hline & $4(1.61)$ & & & & $163(65.7$ \\
\hline Attitude & & $7(2.82)$ & $6(2.42)$ & $68(27.42)$ & 3) \\
\hline Program Cost & $39(15.73)$ & $45(18.15)$ & $22(8.87)$ & $89(35.89)$ & $53(21.37)$ \\
\hline Admission & $5(2.02)$ & & & & \\
\hline Requirements & & $5(2.02)$ & $78(31.45)$ & $85(34.27)$ & $75(30.24)$ \\
\hline & $2(0.81)$ & & & & $107(43.1$ \\
\hline Autonomy Support & & $8(3.23)$ & $23(9.27)$ & $108(43.55)$ & 5) \\
\hline & $1(0.40)$ & & & & $187(75.4$ \\
\hline Self-Efficacy & & $1(0.40)$ & $11(4.44)$ & $48(19.35)$ & o) \\
\hline Social Support & $5(2.02)$ & $26(10.48)$ & $69(27.82)$ & $82(33.06)$ & $66(26.61)$ \\
\hline & $100(40.3$ & & & & \\
\hline Child Care & 2) & $63(25.40)$ & $15(6.05)$ & $25(10.08)$ & $45(18.15)$ \\
\hline Curriculum \& & $\mathrm{O}(.00)$ & & $101(40.7$ & & \\
\hline Instruction & & $17(6.85)$ & 3) & $116(46.77)$ & $14(5.65)$ \\
\hline Political interference & $60(24.19)$ & $41(16.53)$ & $29(11.69)$ & $39(15.73)$ & $79(31.85)$ \\
\hline Program Goals & $3(1.21)$ & & & & $128(51.6$ \\
\hline Achieved & & $7(2.82)$ & $13(5.24)$ & $97(39.11)$ & 1) \\
\hline
\end{tabular}

\section{Estimated $\log$ odds and odds ratios for predictor variables}

The binary logistic regression model had parameter estimates for education, marital status, and grade level taught not converging to real numbers (separation problem). For instance, the parameter estimates for education, marital status, and grade level taught did not converge to real numbers. The results of this study therefore focused on the lasso-penalized logistic regression model.

The secondary purpose of the study was to examine the extent to which the program was achieving its goals, from the perspectives of the untrained teacher trainees. Table 2 presents data on estimated log odds and odds ratios for each predictor variable. Four predictors were important predictors of the response variable: self-efficacy, social support, autonomy support, and attitude. The coefficient for self-efficacy was 0.806, which is interpreted as the expected change in log odds for a one-unit increase in efficacy score. The odds ratio (2.238) implies we expect to see more than two-folds increase in the odds of the 
teacher trainees perceiving the UTDBE to be achieving its goals, for a one-unit increase in efficacy score holding the other covariates and factors fixed.

The coefficient for social support was 0.493 , which is interpreted as the expected change in log odds for a one-unit increase in social support. The odds ratio (1.637) means we expect to see an approximately $64 \%$ increase in the odds of the teacher trainees perceiving the UTDBE to be achieving its goals, for a one-unit increase in social support score holding the other covariates and factors fixed.

\section{Table 2: Display Log of Odds and Odds Ratio for each Lasso Predictor}

\begin{tabular}{lcc} 
Predictor & Lasso Coefficient (Log Odds) & *Odds Ratio \\
\hline Intercept & -3.649 & 0.026 \\
Teaching Experience & 0.000 & 1.000 \\
Age & 0.000 & 1.000 \\
Child Care & 0.000 & 1.000 \\
Political Interference & 0.000 & 1.000 \\
Curriculum \& Instruction & 0.000 & 1.000 \\
Self-Efficacy & 0.806 & 2.238 \\
Social Support & 0.493 & 1.637 \\
Admission Requirements & 0.000 & 1.000 \\
Program Cost & 0.000 & 1.000 \\
Autonomy Support & 0.008 & 1.008 \\
Attitude & 0.155 & 1.168 \\
Year in Training & 0.000 & 1.000 \\
**Grade Level Taught & 0.000 & 1.000 \\
**Education & 0.000 & 1.000 \\
$* *$ Sex & 0.000 & 1.000 \\
**Marital Status & 0.000 & 1.000 \\
\hline
\end{tabular}

*Odds Ratio is obtained by exponentiating the lasso coefficient (log odds).

** All levels were shrunk to zero (refer to Table 1 for the levels).

The coefficient of autonomy support and attitude were 0.008 and 0.155 respectively. They are interpreted as the expected change in log odds for a one-unit increase in AUT and ATT respectively. Their odds ratios (1.008 and 1.168 respectively) imply we expect to see approximately $1 \%$ and $17 \%$ increases in the odds of the trainees believing that the UTDBE was achieving its goals, for a one-unit increase in autonomy support and attitude scores respectively, holding the other covariates and factors fixed. Predictor variables with odds ratio of 1 were the variables that lasso-penalized logistic regression model shrunk to exactly zero and therefore not important predictors of the response variable.

\section{Discussion and Conclusions}

The present study utilized the bioecological model to examine untrained teacher trainees' perceptions about the prospects and challenges of upgrading untrained teachers through the Untrained Teachers Diploma in Basic Education program in Ghana. The results 
indicated some promise in terms of trainees' self-efficacy, social support, autonomysupportive teacher education classrooms, and attitudes toward the program. An overwhelming number of the trainees indicated that the program was achieving its goals to some degree by assisting untrained teachers to have access to professional teacher training and improving the quality of teaching (MOE, 2012; GES, 2003). In addition, the results identified two main challenges facing the program: lack of provision of childcare services for nursing mothers and political interference.

In this section, we discuss the major findings from the study. First, most untrained teacher trainees in the present study indicated they had high levels of self-efficacy. Untrained teacher trainees in the present study reported the teacher education program had increased their confidence and morale as teachers. Self-efficacy or students' beliefs in their own abilities have a significant role in predicting positive academic adjustment outcomes (Fan \& Williams, 2018). That is, students who believe more in their competence to manage their academic activities are likely to have higher degrees of academic adjustment than low self-efficacy students even when they face difficulties (Girelli et al., 2018). Furthermore, this finding is consistent with the claim that UTDBE teachers used more practical activities than DBE teachers, because UTDBE teachers have had some teaching experience, and have developed pedagogical skills and in-service professional development (Kwaah \& Palojoki, 2018). However, previous studies in Ghana (Akyeampong, Adu-Yeboah, \& Kwaah, 2018) and other SSA countries (Akyeampong, Lussier, Pryor, \& Westbrook, 2013) suggest that untrained teachers' perceived levels of high self-efficacy may point to exaggeration of their knowledge and confidences.

Second, social support was an important predictor of trainees' perception of their teacher education program. Most trainees indicated their family members and peers were supportive of their participation in the program. That is, trainees' significant others, siblings, parents, extended family members, and peers served as sources of support for their participation in the program. Social support is important for participation in the program as research has shown that financial challenges and marital issues have resulted in some trainees dropping out of non-traditional teacher preparation programs (Associates for Change, 2016). Informal social support such as from family is often preferred since it is considered as one of the obligations of the kinship system in SSA (Nukunya, 2003).

Third, autonomy support was another important predictor of trainees' perceptions as to whether the non-traditional teacher preparation program in this study was achieving its goals to some degree. Untrained teacher trainees in the present study indicated their tutors/lecturers were tolerant of their opinions in class, encouraged them to experiment with their own teaching method, and were comfortable sharing their feelings with their tutors/lecturers. Autonomy-supportive teachers provide students with necessary information while encouraging them to use the information to solve problems in their own way (Black \& Deci, 2000). Sources of autonomy support can influence students' perceptions of self-efficacy and intrinsic motivation at the university (Jang, Reeve, \& Halusic, 2016). Students who perceive their teachers as more autonomy-supportive perform better over and above differences explained by students' abilities (Black \& Deci, 2000). This finding is significant, as research shows that classroom interactions in Sub-Saharan Africa are typically teacher-oriented (Dei, 2004) with limited student engagement (Pryor \& Akwesi, 1998). Giving teacher trainees some degree of autonomy is in consonance with appropriate practice of a more interactive, learner-focused approach to teacher education.

Fourth, most trainees indicated they had positive attitudes toward the program. Students who have positive attitudes toward a subject would more likely experience academic 
success than those with negative attitudes (Popham, 2005). This finding contradicts that of a previous study which reported that only $38.38 \%$ of untrained teacher trainees reported positive attitudes toward the program (Sofo \& Thompson, 2018). Furthermore, research shows that attitude is a strong predictor of an individual's engagement in a behavior (Fishbein \& Ajzen, 2010). That is, teacher trainees with positive attitudes toward their teacher education program would more likely continue to participate in it and encourage prospective trainees to enroll in the program.

Fifth, slightly over $28 \%$ of the teacher trainees indicated childcare facilities were provided during the residential component of the program at the colleges of education. It is critical that teacher education programs provide such amenities that would allow nursing mothers to successfully complete their teacher training. As Sutherland-Addy (2008) noted, lack of female teachers is a major issue that affects gender disparities in education, especially at the basic education level. Female students see female teachers as role models; as such their successful completion of teacher education programs would serve as a source of motivation to young girls, especially those in basic schools. According to Casely-Hayford (2000) as cited in Casely-Hayford and Hartwell (2010), the poor perception of girls' education in SubSaharan Africa, especially in the deprived areas, encourages parental preference for boys' education due to the traditional roles of the girl child. Furthermore, research shows that maternal education is positively associated with the utilization of social services. For example, women who had attained secondary education utilized more skilled maternity services than those with no formal education (Ganle, Parker, Fitzpartick, \& Otupiri, 2014). Thus, all the necessary steps should be taken by policy makers and educational administrators to promote the training of female teachers who, in turn, would serve as role models to girl child education.

Finally, slightly more than $47 \%$ of the trainees in the present study indicated that political interference negatively impacted the implementation of the program. Often, political parties in developing countries, especially SSA, focus on high visibility projects such as structures and social incentive packages to gain the support of teachers and the youth (Casely-Hayford, 2011). In addition, limited quotas are given for the hiring of untrained teachers to fill the gaps in deprived schools. Access to these quotas has become increasingly difficult due to lack of transparency in the selection process (Associates for Change, 2014), often due to political interference. Furthermore, political party activists are gradually gaining underserved influence over public educational institutions in SSA, creating obstacles for the day-to-day running of these institutions. It is common practice for political party activists of opposing parties in these countries to fight over control of programs in public institutions with a change in government. Many well-intended teacher education programs, especially non-traditional programs, would not realize their goals if politicians in SSA and developing countries in general do not allow teacher educators and educational administrators to do the work they have been trained to do.

In summary, we draw three main conclusions from the findings in the present study. First, the untrained trainees in the present study overwhelmingly indicated that nontraditional teacher education programs can achieve the goals of preparing qualified teachers to some degree. This suggests that the trainees agreed, to some degree, that the program was succeeding in assisting them in becoming professional teachers. Second, the study revealed personal (self-efficacy and attitude) and environmental (social support, autonomy supportive teacher education classrooms) factors that showed promise for the implementation of nontraditional teacher education programs. Finally, the study identified two challenges that could potentially serve as obstacles to non-traditional teacher education programs. The 
challenges were the lack of provision of childcare facilities on college of education campuses and political interference.

\section{Implications for Teacher Education}

The findings of the present study have implications for teacher education in SSA and developing countries in general. First, in-service teacher education programs may lead to better student learning than longer and more costly traditional preservice training programs (World Bank, 2012). This format allows the untrained teacher trainees to receive professional training in the communities in which they live and teach. In addition, most trained teachers posted to their districts refused to report, owing to the deprivation status of the communities where they were to reside and teach (Associates for Change, 2016). Second, rural areas in SSA and other low-income regions experience limited access to equal opportunities as their urban counterparts due to their unique geographical locations and economic and sociocultural characteristics (Miller, 2015). It is imperative for governments and partners in the private sector to prioritize the provision of educational and social amenities in the rural areas. This would discourage the youth from migrating to the urban areas with the associated social problems. The provision of these amenities would also attract trained teachers and provide quality educational resources for the schools in those areas. Third, educational reforms should focus on the inequities in the quality of education, teacher accountability, and teacher deployment (Casely-Hayford, 2011). This would ensure genuine efforts at increasing the supply of qualified teachers (UN, 2015), rather than prioritizing the achievement of party manifesto for political expediency at the expense of the millions of children who need and deserve quality education.

\section{Future Research}

The present study examined untrained teacher trainees' perceptions about the prospects and challenges of a non-traditional teacher preparation program, the Untrained Teachers Diploma in Basic Education program in Ghana. More research is warranted to better understand trainees' perceptions of their teacher education programs. First, the present study examined the sources of social support, but did not examine the types of support family and peers offered the trainees during their participation in the program. Second, the study did not include school climate of the in-service component of the program. For example, a study of the type of climate provided by the headteachers/headmasters of the untrained trainees would provide more insight into the nature of the workplace environment. Third, a study of the pedagogical practices of the tutors/lecturers at the colleges of education during the residential component of the program would provide invaluable information for policymakers and teacher educators in producing high-caliber teachers.

\section{References}

Adentwi, K. L. (2002). Principles and issues in teacher education. Kumasi: Skies Printing Press. Akyeampong, K., Adu-Yeboah, C., \& Kwaah, C. Y. (2018). Assessing the actual needs of untrained teachers with previous teaching experience in Ghana. In Y. Sayeed (Ed.), Continuing professional teacher development in sub-Saharan Africa: Improving teaching and learning (57-81). London: Bloomsbury Academic.

Akyeampong, K., Lussier, K., Pryor, J. \& Westbrook, J. (2013). Improving teaching and learning of basic maths and reading in Africa: Does teacher preparation count? International Journal of Educational Development, 33, 272-282. 
Associates for Change (2014). TENI learning question II: The value addition of volunteer teachers to quality education in Northern Ghana. Final synthesis report. Associates for Change.

Associates for Change (2016). The impact assessment of the untrained teacher diploma in basic education (UTDBE) in Ghana. Endline Study.

Black, A. E., \& Deci, E. L. (2000). The effects of instructors' autonomy support and students' autonomous motivation on learning organic chemistry: A selfdetermination theory perspective. Science Education, 84(6), 740-756. Retrieved from https://onlinelibrary.wiley.com/doi/epdf/10.1002/1098237X\%28200011\%2984\%3A6\%3C740\%3A\%3AAID-SCE4\%3E3.0.CO\%3B2-3

Bolda, T., Filmer, D., Martin, G., Molina, E., Rockmore, C., Stacy, B., ... Wane, W. (2017). What do teachers know and do? Does it matter? Evidence from primary schools in Africa. Policy Research Working Paper [Number 7956]. World Bank Group.

Bronfenbrenner, U. (2005). Making human beings human: Bioecological perspectives on human development. Thousand Oaks, CA: Sage Publications.

Bronfenbrenner, U., \& Morris, P. A. (1998). The ecology of developmental processes. In W. Damon, \& R. M. Lerner (Eds.), Handbook of child psychology, Vol. 1: Theoretical models of human development (993-1028). New York: John Wiley.

Casely-Hayford, L. (2003). Reaching underserved populations with basic education in deprived areas of Ghana: Emerging good practices, Section 1 and Section 2. Accra: CARE.

Casely-Hayford, L. (2011). The political economy analysis of the education sector in Ghana: The implications for STAR-Ghana. STAR-Ghana.

Casely-Hayford, L., \& Hartwell, A. (2010). Reaching the underserved with complementary education: Lessons from Ghana's state and non-state sectors. Development in Practice, 20(4-5), 527-39.

Dei, G. J. S. (2004). Schooling and education in Africa: The case of Ghana. Trenton, NJ: Africa World Press, Inc.

Effron, R, \& Hastie, T. (2016). Computer age statistical inference: Algorithms, evidence, and data science. New York, NY: Cambridge University Press.

Fan, W., \& Williams, C. (2018). The mediating role of student motivation in the linking of perceived school climate and achievement in reading and mathematics. Frontiers in Education, 3, 1-12. doi: 10.3389/feduc.2018.00050.

Farrell, J., \& Hartwell, A. (2008). Planning for successful alternative education: A possible route to education for all. Paris: International Institute for Educational Planning/UNESCO.

Fishbein, M., \& Ajzen, I. (2010). Predicting and changing behavior: The reasoned action approach. New York, NY: Psychology Press.

Ganle, J. K., Parker, M., Fitzpartick, R., \& Otupiri, E. (2014). Inequities in accessibility to and utilisation of maternal health services in Ghana after user-fee exemption: A descriptive study. International Journal for Equity in Health, 13, 89. doi: 10.1186/s12939-014-0089-z.

Geyer, C. J. (2009). Likelihood inference in exponential families and directions of recession. Electronic Journal of Statistics 3, 259-89.

Ghana Education Service (2003). Handbook for UTDBE programme through distance education, Accra: GES. 
Girelli, L., Alivernini, F., Lucidi, F., Cozzolino, M., Savarese, G. Sibilio, M. (2018). Autonomy supportive contexts, autonomous motivation, and self-efficacy predict academic adjustment of first-year university students. Frontier in Education. doi: https://doi.org/10.3389/feduc.2018.00095.

Jang, H., Reeve, J., \& Halusic, M. (2016). A new autonomy-supportive way of teaching that increases conceptual learning: Teaching in students' preferred ways. The Journal of Experimental Education, 84(4), 686-701. doi: 10.1080/00220973.2015.1083522.

Kwaah, C. Y., \& Palojoki, P. (2018). Entry characteristics, academic achievement and teaching practices: A comparative study of two categories of newly qualified teachers in basic schools in Ghana. Cogent Education, 5, 1-19. doi: https://doi.org/10.1080/2331186X.2018.1561144.

Lee, J. D., Sun, Y., \& Saunders, M. A. (2014). Proximal Newton-Type methods for minimizing composite functions. SIAM Journal on Optimization, 24(3), 1420-1443.

Miller, P. (2015). Leading remotely: Exploring the experiences of principals in rural and remote school communities in Jamaica. International Journal of Whole Schooling, 11 (1), 35-53.

Ministry of Education (2012). Education sector performance report. Accra: Ministry of Education.

Mulkeen, A. (2010). Teachers in anglophone Africa: Issues in teacher supply, training and management. Washington, DC: World Bank.

Ndabaga, E., Ntahomvukiye, C., \& Omar, Y. (2018). Key initiatives in Rwandan teachers' CPD after the 1994 genocide against the Tutsi. In Y. Sayed (Ed.), Continuing professional teacher development in Sub-Saharan Africa: Improving teaching and learning (109-126). London: Bloomsbury Academic.

Nukunya, G. K. (2003). Tradition and change in Ghana: An introduction to sociology (2 $2^{\text {nd }}$ ed.). Accra: Ghana Universities Press.

Palmer, R. (2005) Beyond the basics: Post-basic education and training and poverty reduction in Ghana. Post-Basic Education and Training Working Paper Series No 4, Edinburgh: Centre of African Studies, University of Edinburgh. Retrieved from https://assets.publishing.service.gov.uk/media/57a08c5be5274a31e0001 172/Palme r_Ghana_PBET_WP4.pdf.

Popham, W. (2005). Students' attitudes count. Educational Leadership, 62(5), 84-85.

Pryor, J., \& Akwesi, C. (1998). Assessment in Ghana and England: Putting reforms to the test of practice. Compare, 28(3), 263-275.

Rainey, C. (2016). Dealing with separation in logistic regression models. Political Analysis, 24(3), 339-355. doi:10.1093/pan/mpw014.

Sayed, Y., Badroodien, A., Salmon, T. \& McDonald, Z. (2016). Social cohesion and initial teacher education in South Africa. Educational Research for Social Change, 5(1), 54-69. doi: http://dx.doi.org/10.17159/2221-4070/2016/v5i1a4.

Sofo, S., \& Thompson, E. (2018). Teacher trainees' attitudes toward the untrained teachers diploma in basic education program in Ghana. Journal of Education and Practice, 9(3), 101-107.

Sutherland-Addy, E. (2008). Gender equity in junior and senior secondary education in Ghana. World Bank Working Paper No. 140. Washington, D.C.

Tudge, J. R., Mokrova, I., Hatfield, B. E., \& Karnik, R. B. (2009). Uses and misuses of Bronfenbrenner's bioecological theory of human development. Journal of Family Review and Theory, 1(4), 198-210. doi: https://doi.org/10.1111/j.17562589.2009.00026.x. 
UNESCO (2014). EFA global monitoring report: Teaching and learning-Achieving quality for all. Paris: UNESCO.

United Nations (2015). Transforming our world: The 2030 agenda for sustainable development (A/RES/70/1). Retrieved January 22, 2019 from https://sustainabledevelopment.un.org/content/documents/2 1252030\%20Agenda \%20for\%20Sustainable\%20Development\%20web.pdf.

World Bank (2012). Education in Sub-Saharan Africa: A comparative analysis. A World Bank Study. Washington, D.C.: The World Bank:

World Bank (2018). Ghana priorities for ending poverty and boosting shared prosperity: Systematic country diagnostic [Report No. 132010-GH].

Zorn, Christopher (2005). A solution to separation in binary response models. Political Analysis, 13(2), 157-70.

\section{About the Authors}

Seidu Sofo is a full Professor of Physical Education Teacher Education at Southeast Missouri State University. His academic and research interests are in physical education pedagogy, teacher education, perceptual-motor development, children' physical activity, and postcolonial pedagogy. He holds a Ph.D. in Human Performance Studies with a concentration in Physical Education Pedagogy from The University of Alabama, USA. He obtained a MS.Ed. (Physical Education Pedagogy) from the State University of New York College at Brockport, NY. Prior to that, he had graduated from the University of Cape Coast, Ghana, with a B.Ed. in Physical Education, and a Diploma in Biology.

Emmanuel Thompson is an Associate Professor of Actuarial Science. He coordinates the undergraduate actuarial science program and graduate programs in the academic department at his institution. Thompson's current research interests include actuarial risk theory, panel data models, financial time series, application of statistical and machine learning models to actuarial, insurance, and business problems, and econometrics. He is an associate of the Actuarial Society of Ghana and an affiliate of the Institute and Faculty of Actuaries in the United Kingdom. He is a certified Graduate Statistician by the American Statistical Association. Emmanuel holds a Ph.D. in Statistics (Actuarial Science option) and a Master of Science in Actuarial Science both from the University of Calgary in Canada. He holds a B.Sc. in Statistics from the University of Cape Coast, Ghana. Thompson worked in various capacities with insurance companies in life insurance, personal and commercial lines insurance, research, investment, and statistics.

Tontie L. Kanton is a doctoral fellow with the Institute of African Studies at the University of Ghana, Ghana. His Ph.D. program is a collaboration between the University of Ghana and the Department of Geoscience and Natural Resources Management at the University of Copenhagen, Denmark. Kanton's research interest is in the environmental outcomes of charcoal production in the savanna and transition zones in Ghana. He obtained his master's and bachelor's degrees from the University of Ghana and the University of Cape Coast, Ghana respectively. 


\section{APPENDIX A \\ UTDBE PERCEPTIONS QUESTIONNAIRE}

The purpose of this questionnaire is to examine your perceptions about the Untrained Teachers Diploma in Basic Education program (UTDBE) that you are currently pursuing.

\section{PART I: (Check one)}

This section examines the extent to which the following statements describe your views about the Untrained Teachers Diploma in Basic Education program, referred to as the "program."

Please rate each of the statements below as: Strongly Agree (SA); Agree (A); Neutral (N); Disagree (D); or Strongly Disagree (SD), by checking the appropriate box.

\begin{tabular}{|c|c|c|c|c|c|}
\hline Statement & SA & A & $\mathrm{N}$ & $\mathrm{D}$ & $\mathrm{SD}$ \\
\hline & 5 & 4 & 3 & 2 & 1 \\
\hline $\begin{array}{l}\text { 1. Most UTDBE trainees have positive attitudes toward learning in } \\
\text { the UTDBE program. }\end{array}$ & & & & & \\
\hline 2. I can afford the UTDBE program fees. & & & & & \\
\hline $\begin{array}{l}\text { 3. The UTDBE admission requirements are the same as those of the } \\
\text { colleges of education. }\end{array}$ & & & & & \\
\hline 4. My lecturers are tolerant of my opinions in class. & & & & & \\
\hline $\begin{array}{l}\text { 5. My lecturers encourage me to experiment with my own teaching } \\
\text { methods } \\
\text { and techniques. }\end{array}$ & & & & & \\
\hline 6. I feel comfortable sharing my feelings with my lecturers. & & & & & \\
\hline $\begin{array}{l}\text { 7. The UTDBE program has increased my confidence and morale as } \\
\text { an untrained teacher. }\end{array}$ & & & & & \\
\hline $\begin{array}{l}\text { 8. I rate myself as an academically excellent student in the UTDBE } \\
\text { program. }\end{array}$ & & & & & \\
\hline $\begin{array}{l}\text { 9. My spouse or significant other (husband/wife or } \\
\text { boyfriend/girlfriend) is supportive of my participation in the UTDBE } \\
\text { program. }\end{array}$ & & & & & \\
\hline $\begin{array}{l}\text { 10. My peers (other UTDBE Trainees) are supportive of my } \\
\text { participation in the UTDBE program. }\end{array}$ & & & & & \\
\hline $\begin{array}{l}\text { 11. My siblings (brothers and sisters) are supportive of my } \\
\text { participation in the UTDBE program. }\end{array}$ & & & & & \\
\hline $\begin{array}{l}\text { 12. My parents are supportive of my participation in the UTDBE } \\
\text { program. }\end{array}$ & & & & & \\
\hline $\begin{array}{l}\text { 13. My extended family members (aunts/uncles/cousins etc.) are } \\
\text { supportive of my participation in the UTDBE program. }\end{array}$ & & & & & \\
\hline $\begin{array}{l}\text { 14. The UTDBE program provides childcare services for trainees } \\
\text { who are nursing mothers. }\end{array}$ & & & & & \\
\hline $\begin{array}{l}\text { 15. UTDBE class sizes are similar to those at the Colleges of } \\
\text { Education. }\end{array}$ & & & & & \\
\hline 16. The UTDBE learning modules are of high quality. & & & & & \\
\hline
\end{tabular}




\begin{tabular}{|c|c|c|c|c|c|}
\hline Statement & SA & $\mathrm{A}$ & $\mathrm{N}$ & $\mathrm{D}$ & SD \\
\hline $\begin{array}{l}\text { 17. The number of courses for the UTDBE program should be } \\
\text { reduced. }\end{array}$ & & & & & \\
\hline $\begin{array}{l}\text { 18. There are adequate basic instructional resources (e.g. P.A } \\
\text { systems, } \\
\text { projectors, reference materials, internet facilities etc) for the UTDBE } \\
\text { program. }\end{array}$ & & & & & \\
\hline $\begin{array}{l}\text { 19. Political interference is negatively affecting the implementation of } \\
\text { the UTDBE program. }\end{array}$ & & & & & \\
\hline $\begin{array}{l}\text { 20. In my opinion, the UTDBE program is currently achieving its } \\
\text { goals. }\end{array}$ & & & & & \\
\hline
\end{tabular}

\section{PART II: DEMOGRAPHIC INFORMATION}

21. Year in the UTDBE program (check one): $\_1^{\text {st }} \sim^{2^{\text {nd }}}-^{3^{\text {rd }}}-_{4^{\text {th }}}^{\text {Other }}$

22. Number of years you served as an untrained (pupil) teacher:

23. Grade Level you currently teach (check all that apply): $\mathrm{K} \_\mathrm{P} 1 \_\mathrm{P} 2$ ${ }_{-} \mathrm{P} 4 \_\mathrm{P} 5 \_\mathrm{P} 6$

24. Highest Level of Education Attained:

MSLC BECE (JSS) WASSCE/SSSCE Other

25. Your Age:

26. Your Gender: Male __ Female

27. Marital Status: Married Single Other 28. Region: District:

\section{KEY:}

Listed here are the predictors and their corresponding questionnaire items: Attitude (1); Program Cost (2); , Admission Requirements (3), Autonomy Support (4, 5, 6); Self-Efficacy (7, 8); Social Support (9, 10, 11, 12, 13); Childcare (14); Curriculum and Instruction (15, 16, 17, 18); Political Interference (19); and Program Goals (20). 